\title{
Víctor Hugo en El Salvador. Huellas del autor francés en publicaciones de este país
}

\author{
María del Mar JIMÉNEZ-CERVANTES ARNAO \\ Universidad Católica San Antonio de Murcia \\ Departamento de Idiomas \\ mjimenez@pdi.ucam.edu
}

Recibido: 6 de octubre de 2009

Aceptado: 11 de enero de 2010

\section{RESUMEN}

El objetivo de este artículo es identificar, cuando no se especifica el título, clasificar y analizar los textos publicados a finales del siglo XIX y principios del XX en El Salvador en los que hemos encontrado alusiones, traducciones o citas extraídas de obras de Victor Hugo. De los cuarenta y seis que suman en total, hay ocho referencias, nueve citas y veintinueve traducciones de poemas o de textos en prosa que hemos comparado con los originales, estableciendo las diferencias entre las dos versiones.

Palabras clave: El Salvador, siglos XIX y XX, Victor Hugo, traducciones, citas, referencias.

\section{Victor Hugo au Salvador.}

\section{Les traces de l'auteur français dans des publications du Salvador}

\section{RÉSUMÉ}

Le but de cet article est d'identifier, lorsque le litre n'est pas donné, classer et analyser les textes publiés où il y a des références, des citations ou des traductions d'œuvres de Victor Hugo vers la fin du XIX ${ }^{\text {ème }}$ siècle et le commencement du XX ${ }^{\text {ème }}$ au Salvador. Parmi les quarante-six textes, il y a huit références, neuf citations et vingt-neuf traductions de poésies ou textes en prose que nous avons confrontés aux originaux en établissant les différences entre les deux versions.

Mots clés: El Salvador, XIX ${ }^{\text {ème }}$ et $\mathrm{XX}^{\text {ème }}$ siècles, Victor Hugo, traductions, citations, références.

\section{Victor Hugo in El Salvador. \\ Traces of the French writer in El Salvador publications'}

\begin{abstract}
This paper aims to identify, classify and analyze texts containing references to, quotations from, or translations of Victor Hugo's work, published in El Salvador in the late nineteenth and early twentieth centuries. Among the forty-six texts analyzed, there are eight references, nine quotations and twentynine translated poems and prose texts, which, once compared to their French originals, have helped us define the differences between both versions.
\end{abstract}

Key words: El Salvador, XIX and XX centuries, Victor Hugo, translations, quotations, references. 
Sumario: 1 . Traducciones - 2. Citas -3 . Referencias -4 . Tablas y conclusiones

Que Victor Hugo es uno de los autores más importantes de la literatura francesa y universal del siglo XIX es un hecho que no se pone en duda. Su longeva vida, que comienza y termina casi con el siglo, añadida a su amplia producción literaria y a la variedad de géneros y temas abordados le permite incluso llegar a ser una suerte de icono literario de ese periodo de tiempo. Como figura internacionalmente reconocida por su importancia y alcance, no es de extrañar que haya sido leído, traducido e imitado en diferentes países de todo el mundo. Las letras hispanoamericanas de ese mismo siglo XIX, reflejo del despertar de sus naciones, se independizan de la literatura de la antigua metrópoli $\mathrm{y}$, coincidiendo con el movimiento romántico, miran hacia otras producciones literarias: estadounidense, alemana o francesa en las que encuentran inspiración o influencia. Esta influencia internacional y principalmente francesa, unida a la identidad americana produjeron el nacimiento del modernismo hacia finales del siglo XIX (Bellini 1997: 248).

El Salvador, como país centroamericano inmerso en esta "revolución" primero nacional y luego literaria de su continente, es partícipe activo del nacimiento de sus letras mediante la aparición de revistas donde publican autores salvadoreños y latinoamericanos así como traducciones de escritores internacionales. De esta manera, podemos encontrar textos traducidos, citas o referencias a Victor Hugo en diferentes publicaciones de entre finales del siglo XIX y principios del XX de la República de El Salvador. Las revistas consultadas son las siguientes: La Quincena, tomos de los años 1903 a 1907, El Repertorio de los años 1906 a 1907, y La Guirnalda Salvadoreña, antología de poetas salvadoreños realizada por Román Mayorga Rivas y publicada en tres volúmenes en los años 1884 a 1886. Además, contamos con textos de Hugo pertenecientes a otras publicaciones de este mismo país y en esta época, resultantes de la búsqueda de información sobre el autor salvadoreño Francisco Gavidia, uno de los introductores y difusores de la literatura francesa en el país centroamericano. No todos los textos que hemos encontrado sobre Victor Hugo son traducciones de obras suyas, también tenemos citas y referencias a su vida o a su obra. Del mismo modo, vamos a leer textos en los que se identifica al traductor así como otros en los que éste no es mencionado, o en cambio no se nombra la obra traducida o de la que se extrae la cita, elementos que dificultaron la búsqueda esos textos, llegando a imposibilitar la identificación en algunos casos, como veremos más adelante. Otro aspecto que hay que señalar es que hay citas que se incluyen en francés acompañando a textos literarios o artículos, dejando así constancia de la competencia de los escritores y lectores de las publicaciones en ese idioma.

\section{Traducciones}

Victor Hugo es el autor francés que más textos literarios tiene publicados en las revistas salvadoreñas estudiadas. Siguiendo el orden cronológico de publicación en 
La Quincena, el primer texto que encontramos es "Toute la lira", traducido por Leopoldo Díaz. Le sigue la traducción de "Stella" publicada el 1 de enero de 1904 mediante la cual Francisco Gavidia presenta el resultado de su trabajo sobre la adaptación del alejandrino francés a la lengua castellana. En el número siguiente, el del 15 de enero de ese mismo año encontramos "El derecho de la miseria", poema traducido por Marcos Rafael Blanco-Belmonte. El 1 de febrero también de 1904 se publica "El Alfabeto", texto en prosa, seguido de otro texto en prosa "Victor Hugo pintado por sí mismo" el 15 de abril de 1904. A lo largo del año 1905 aparecen tres traducciones más de Victor Hugo: el 1 de marzo podemos leer fragmentos de la obra William Shakespeare sin título alguno; el 15 de abril y bajo el título "Líneas" hay otro texto de Hugo; y para terminar ese año, el 15 de agosto se publica "La novia del timbalero". El último texto traducido de Hugo en La Quincena es el poema "Las Estrellas", el 15 de febrero de 1907.

En la sección fija llamada "Notas y Noticias" de la revista La Quincena del 1 de noviembre de 1903 aparece el poema "Toute la Lira" traducido por Leopoldo Díaz. En realidad se trata de la versión en español de la poesía titulada "Vous m'avez éprouvé", incluida en el poemario póstumo titulado Toute la lyre. El original está formado por veinticuatro versos alejandrinos franceses pareados de rima rica (Hugo s.f.: 259-260). La traducción realizada por Leopoldo Díaz cuenta con veintiséis versos endecasílabos sin rima. Es interesante la elección del traductor, que utiliza el título del poemario para darle nombre a la poesía dejando una parte en francés y traduciendo el resto.

El 1 de enero de 1904 Francisco Gavidia presenta en La Quincena su trabajo sobre la adaptación del verso alejandrino francés al castellano, ilustrándolo con la traducción del poema "Stella", publicado por Hugo en su libro Les Châtiments. En lo referente a la estructura del poema podemos decir que Hugo utilizó cuarenta y dos versos alejandrinos franceses pareados de rima rica (Hugo 1964: 178), mientras que Gavidia publica un poema de cuarenta y cuatro versos de catorce sílabas, alejandrino español, utilizando la rima consonante en versos igualmente pareados ${ }^{1}$.

"El derecho de la miseria", publicado en el número del 15 de enero de 1904 de La Quincena, está firmado por Marcos Rafael Blanco-Belmonte. Al no haber encontrado el texto original ${ }^{2}$, no podemos hacer una comparación con la traducción. El texto en español está formado por veinte versos endecasílabos y heptasílabos, es decir, la estructura de una silva con rima consonante en serventesios ABAB.

El cuarto texto de Victor Hugo publicado en La Quincena es "El Alfabeto", que vio la luz el 1 de febrero de 1904. Se trata de la traducción de parte de un fragmento

\footnotetext{
1 Para un análisis en profundidad del aspecto formal de esta traducción consúltese JiménezCervantes Arnao, 2008.

${ }^{2}$ Ante la dificultad de encontrar un texto con un título que no se corresponde con el del original realizamos una traducción inversa a partir del texto en castellano, tratando de identificar elementos que hayan podido ser trasladados de forma más literal desde el francés; si el primero no resulta, otro recurso utilizado es buscar referencias del traductor por si hubiera una antología de su trabajo o un repertorio de las obras traducidas. Aunque en otros casos estas acciones tuvieron éxito, no fue así en el texto firmado por Blanco-Belmonte.
} 
de un texto en prosa incluido en Alpes et Pyrénées, publicado en 1839 (Hugo 1987: 684). La traducción no aparece firmada.

El 15 de abril de 1904 aparece el texto titulado "Victor Hugo pintado por sí mismo" sin que de nuevo esté firmado por ningún traductor. En él, tras una introducción aclarando que se trata de un retrato realizado por el poeta francés, se inserta entre comillas un texto en prosa en el que el propio Hugo reflexiona sobre su posición política haciendo referencia también a algunas de sus obras en las que él reflejó esta postura. No hemos encontrado tampoco el texto original.

En el número de La Quincena del 1 de marzo de 1905 encontramos un texto que se asemeja a una reseña sobre el autor, puesto que aparece al final de página, sin título y sin nombre de traductor. Sin embargo, en realidad se trata de fragmentos de la obra William Shakespeare. Esta obra nace de la intención de Hugo de escribir la biografía del dramaturgo inglés como prólogo para una traducción de su hijo, pero que terminó siendo una obra más del autor francés, publicada en 1865, estando aún en el exilio. El texto en español resulta de la traducción de fragmentos no consecutivos de "Le dix-neuvième siècle" el segundo libro de la tercera parte del libro (Hugo 2003: 316-317). El traductor comete un error en la versión en castellano puesto que traduce est desagréable aux intelligences saturées d'ignorance (Hugo 2003: 316) por Debe ser muy agradable para las inteligencias saturadas de ignorancia.

Bajo el título "Líneas" podemos leer en el número del 15 de abril de 1905 de la misma revista la traducción y adaptación en prosa del poema de Hugo "Je n'ai pas de palais épiscopal en ville", incluido en L'Année Terrible, poemario publicado en 1872, estando el poeta ya de vuelta en Francia tras su exilio. El poema original consta de cuarenta versos alejandrinos franceses pareados de rima rica (Hugo 1974: 416) que son traducidos de una forma muy literal en el texto en prosa en español salvo por la omisión de los versos número diez y once.

"La novia del timbalero", publicado en el mismo número de La Quincena del 15 de abril de 1905, es la traducción de "La fiancée du timbalier", poema incluido en Odes et Ballades, publicado en 1827, cuando Hugo tenía veinticinco años. Este poema pertenece por lo tanto a la primera época literaria del autor. El original está formado por veinte estrofas de cinco versos octosílabos de rima rica siguiendo el siguiente esquema: ABAAB (Hugo 1950: 510). Sin embargo, la traducción realizada por José Juan Tablada presenta ciertas modificaciones respecto al poema escrito por Victor Hugo: en lugar de veinte utiliza diecinueve quintetos, el traductor elimina la quinta estrofa. Los versos utilizados son de nueve sílabas y con una rima consonante, pero la distribución de ésta ya no es constante a lo largo de todo el poema como ocurre en el texto original, sino que Tablada alterna el esquema ABAAB con ABABA.

El último de los textos de Victor Hugo que hemos encontrado en los números consultados de La Quincena aparece en el $\mathrm{n}^{\circ} 83$ de la revista, publicado el 15 de febrero de 1907. El poema se titula en español "Las Estrellas", lo que nos ha dificultado bastante la búsqueda del original, que hemos conseguido identificar como la traducción de "Extase", poema incluido en Les Orientales (Hugo 1964: 680) y formado por doce versos distribuidos en dos estrofas de seis. Los cinco 
primeros versos son alejandrinos franceses y el sexto es un octosílabo, y tienen una rima rica distribuida en AABCCB. La traducción es un poema compuesto por cuatro estrofas de cuatro versos, los tres primeros son endecasílabos y el último es un heptasílabo. La rima utilizada por el traductor es consonante distribuida en $\mathrm{ABAb}$, serventesios.

De los nueve textos arriba analizados, en siete conocemos la obra de la que procede el texto y sólo en cuatro de ellos aparece escrito el nombre del traductor.

Por último, y aunque no se trate de una traducción, queremos resaltar la influencia de Victor Hugo patente en el poema "Remember fúnebre" de Juan Antonio Solórzano, publicado el 1 de noviembre de 1906 de esta revista. Se trata de una "Paráfrasis de Victor Hugo"3 anunciada por el autor bajo el título, en la que llora la muerte de su hija Lilia, a la que hace referencia en tres ocasiones a lo largo de la poesía. Probablemente el poeta tomara como modelo alguno de los poemas de Les Contemplations, pero no hemos encontrado uno que sea particularmente más cercano a éste. Se trata de una composición que suma doce estrofas de cuatro versos endecasílabos con rima asonante alterna en los pares.

Al igual que ocurre en La Quincena, Victor Hugo es el autor francés más publicado en El Repertorio, llegando a superar la cantidad de la otra revista, que era nueve, ya que, tenemos trece textos publicados en tres años.

El primero de ellos, titulado "La libertad de la prensa", editado el 1 de marzo de 1906, es la traducción de fragmentos del capítulo "Les Misérables", incluido en "Pendant l'exil" de Actes et Paroles. El traductor, A. Gordon de San Simón, no reproduce todo el texto en prosa del original, sino que, además de escoger la parte central del discurso para hacer la traducción, omite párrafos de la parte elegida, lo que, unido al cambio de título, resulta un texto bastante diferente del que parte y no fácil de identificar.

En el número siguiente de El Repertorio, el del 15 de marzo de 1906, se encuentra otro texto procedente de "Pendant l'exil" de Actes et Paroles. Se trata de "Au Président de la République Mexicaine", una carta mediante la cual Victor Hugo solicita a Benito Juárez que le perdone la vida al emperador Maximiliano, pudiendo convertirse mediante la indulgencia en uno de los héroes americanos (Hugo 1992: 226). Al igual que en el caso anterior, no se trata de la traducción íntegra del texto original. El traductor, que no es identificado, omite ciertos párrafos de la carta original, aunque no llega a realizar una modificación tan importante como la vista en el texto "La libertad de la prensa". En cuanto al título en español, se reduce a un genérico "Una carta", seguido de la fecha y el lugar donde se escribió, información que aparece al final del texto en el original.

El siguiente texto, titulado "Redemptio", apareció el 1 de abril de 1906 tras un texto en prosa dedicado "A la mujer caída" que cita el poema de Hugo. Se trata de la traducción de "Oh! N'insultez jamais une femme qui tombe", poema formado por dieciséis versos alejandrinos franceses pareados con rima rica incluido en Les Chants du crépuscule (Hugo 1964: 858). Gregorio Gutiérrez González, el traductor,

\footnotetext{
${ }^{3}$ Según la segunda acepción del Diccionario de la Real Academia, una paráfrasis es: Traducción en verso en la cual se imita el original, sin verterlo con escrupulosa exactitud (www.rae.es).
} 
además de darle un título en latín a la poesía ${ }^{4}$, cambia la estructura al utilizar cinco serventesios endecasílabos de rima consonante, con lo que añade cuatro versos. Podemos decir que este texto es completo puesto que informa tanto del autor original como del traductor.

En ese mismo número de El Repertorio del 1 de abril de 1906 podemos leer otro texto de Victor Hugo, esta vez en prosa. Bajo el título "San Pablo" encontramos la traducción íntegra del texto dedicado al santo en el párrafo X del segundo libro, "Les Génies", de la primera parte de William Shakespeare (Hugo 2003: 99), obra escrita por el autor francés en el exilio en Inglaterra ${ }^{5}$. Bajo el texto aparece el nombre de Victor Hugo, pero no se menciona al traductor.

El 15 de abril de 1906 aparece otro texto en prosa del autor francés: "A un Obispo que me llama ateo y me excomulga". Sin embargo, el original "À l'évêque qui m'appelle athée" es un poema incluido en el libro "Novembre" de L'Année terrible formado por noventa y ocho versos alejandrinos franceses pareados con rima rica (Hugo 1974: 321). Dejando de lado el evidente cambio en la estructura formal, la traducción es bastante literal aunque haya alguna omisión de parte de un verso. Lo que sí nos ha llamado la atención es el tuteo en la poesía en francés, Victor Hugo utiliza un tono familiar dirigiéndose de tú al obispo con los pronombres tien y toi. El texto en español se sirve del posesivo tuyo y en el segundo caso utiliza la forma vos. En esta ocasión tampoco aparece el nombre del traductor.

El 1 de mayo de ese mismo año se publica en El Repertorio otra traducción de un texto procedente de L'Année terrible. "Les insulteurs", aparece en el libro "Juillet" de la citada obra escrita por Hugo. El original consta de dieciocho versos alejandrinos pareados en rima rica (Hugo 1974: 453). "Los insultadores" es un poema de más de veinte versos ${ }^{6}$ heptasílabos y endecasílabos de rima consonante y sin seguir un patrón determinado, es decir, se trata de una silva. No se especifica el nombre del traductor.

El Repertorio del 1 de junio de 1906 publica otro texto del segundo libro, "Les Génies", de la primera parte de William Shakespeare. En esta ocasión se trata del párrafo I, dedicado a Homero (Hugo 2003: 79). Aunque sigue sin aparecer el nombre del traductor, esta vez el título es más completo que en el caso anterior de "San Pablo": "Los Genios" "Homero". Al igual que en la traducción anteriormente analizada de este mismo libro, se reproduce el párrafo completo e incluye el nombre del autor francés.

En ese mismo año y tan solo un mes después, el 1 de julio de 1906, podemos leer la traducción del poema "À la belle impérieuse", de Les chansons des rues et des bois. El original francés es una poesía compuesta por cuatro estrofas de cuatro

\footnotetext{
4 “Oh! N'insultez jamais une femme qui tombe" es el primer verso del poema, que sirve de título al mismo.

${ }^{5}$ Hugo deja patente su lucha constante contra Louis-Napoléon Bonaparte y su gobierno en este texto terminándolo con una metáfora en la que da a Francia la fuerza de San Pablo, y al igual que él levantará armado con la espada de la revolución.

${ }^{6}$ No tenemos una buena imagen del texto, por lo cual el análisis de esta traducción es incompleta al no tener los últimos versos de la misma.
} 
versos de cinco y cuatro sílabas con rima rica en abab (Hugo 1974: 112). Aunque el traductor respeta el título: "A la bella imperiosa", transforma el poema en prosa y deja de tratar de vous a la receptora de su mensaje para tutearla. De nuevo, desconocemos el nombre del traductor, ya que únicamente aparece el de Victor Hugo.

El siguiente texto del autor de Besançon es "El Momotombo", traducción de "L'Inquisition - Les raisons du Momotombo", de La Légende des Siècles (Hugo 1950: 444). El poema escrito por Victor Hugo consta de cincuenta y cuatro versos alejandrinos franceses pareados de rima rica. La traducción, de la que desconocemos la autoría, es una silva de cincuenta y seis versos, con lo que tan sólo aumenta en uno el número de versos originales. La rima utilizada es consonante aunque no reproduzca ningún patrón. Tanto la poesía original como la traducción van precedidas de una cita de Squier extraída de Voyage dans l'Amérique du Sud, que el traductor reduce a Viajes en América y también traduce. Este texto se publicó en El Repertorio el 15 de agosto de 1906.

El 1 de octubre de 1906 se publica "Crepúsculo", poema traducido por Teodoro Llorente. El original "Crépuscule", incluido en Les Contemplations, es un poema de veintiocho versos distribuidos en siete serventesios de rima rica (Hugo 1964: 563). La traducción resultante es una silva de cincuenta y cuatro versos en rima consonante.

Abriendo El Repertorio del 15 de junio del año 1907 podemos leer "Ecos de una gran voz", firmado por Victor Hugo. Se trata de un texto compuesto de extractos de diferentes discursos o escritos de Hugo, todos incluidos en el mismo libro. El primero es un fragmento perteneciente al discurso "Le Centenaire de Voltaire", que podemos encontrar en "Depuis l'exil" de Actes et Paroles. En el caso del segundo, podemos encontrarlo en otro párrafo, y en esta ocasión el traductor omite más de la mitad del mismo. Se trata de "Sur la tombe de Félix Bony", de "Pendant l'exil". El tercer párrafo ha sido extraído de "Le Droit et la Loi", de "Avant l'exil" del mismo libro. Así pues, el traductor selecciona extractos de diferentes discursos o escritos, los une en un todo y les da un título haciendo ver al lector de El Repertorio que es un texto así creado por Hugo, puesto que no hay mención alguna a las diferentes partes del libro o de que se trate de un texto compuesto por otros tres.

Por último, el 15 de septiembre de 1908 aparecen juntos dos cortos textos en prosa sin que se identifique al traductor: "A la niña enferma durante el sitio" y "A Enrique V". Ambos textos proceden de L'Année Terrible, de los libros "Novembre" y "Juillet" respectivamente. "À l'enfant malade pendant le siège" es un poema formado por veintiocho versos dodecasílabos y hexasílabos distribuidos en siete estrofas de cuatro versos con rima rica en AbAb (Hugo 1974: 324). "À Henri V" es una composición de veintidós versos alejandrinos franceses pareados de rima rica (Hugo 1974: 454). Ambos poemas son traducidos por pequeños textos en prosa.

De todos los trece textos aparecidos y analizados de El Repertorio, sólo en tres ocasiones encontramos el nombre del traductor y en ninguno de ellos se menciona la obra a la que pertenecen.

La Guirnalda Salvadoreña es una publicación de finales del siglo XIX (18841886) en la que Román Mayorga Rivas emprendió la labor antológica de recopilar y 
publicar poemas de los principales poetas salvadoreños del momento. En el capítulo dedicado a Joaquín Méndez aparece una serie de poesías traducidas bajo el título "Versiones y Paráfrasis", ordenadas por autores y que comienza por cuatro de Victor Hugo, todas incluidas en el poemario Les Contemplations: "?", "La naturaleza", "Religión" y "A la que ha quedado en Francia".

El poema "?", incluido en "Les Luttes et les Rêves", el tercer libro de Les Contemplations, está formado por veintidós versos alejandrinos franceses pareados de rima rica (Hugo 1964: 588). Sin embargo, aunque Joaquín Méndez consigue mantener el mismo número de versos, cambia las doce sílabas del alejandrino francés por el endecasílabo blanco.

A continuación le sigue "La naturaleza", perteneciente también al mismo libro de esa recopilación. La versión original de Victor Hugo, "La Nature" cuenta con cuarenta y ocho versos pareados alejandrinos de rima rica (Hugo 1964: 613). La traducción llega a ciento diecinueve versos heptasílabos con rima alterna en los pares, lo que la convierte en un romancillo. De esta forma, el poema de Joaquín Méndez supera en más del doble los versos escritos por Hugo, pero es cierto que los versos en español miden casi la mitad de los franceses.

"Religión", perteneciente al sexto libro, "Au bord de l'infini" es el tercer poema de Hugo traducido por Méndez y el que más respeta el formato original establecido por el poeta francés. "Relligio" tiene un total de veinticuatro versos distribuidos en estrofas de seis, formando tercetos encadenados dodecasílabos (los dos primeros) y octosílabos (el tercero). La rima es rica, distribuida en $12 \mathrm{~A} 12 \mathrm{~A} 8 \mathrm{~b}-12 \mathrm{C} 12 \mathrm{C} 8 \mathrm{~b}$ (Hugo 1964: 777). La traducción reproduce fielmente el esquema métrico usado por Hugo en el mismo número de versos, la única diferencia entre las dos versiones es que el autor salvadoreño utiliza en todos los versos el alejandrino español.

El último poema traducido de Hugo por Joaquín Méndez que se publicó en $L a$ Guirnalda Salvadoreña es "A la que ha quedado en Francia", poema con el que Victor Hugo cierra Les Contemplations y que dedica a su hija Léopoldine, muerta en 1843 y enterrada en Francia ${ }^{7}$. Se trata de un largo poema de trescientos cincuenta versos alejandrinos franceses pareados de rima rica distribuidos en siete partes (Hugo 1964: 823). La traducción del autor salvadoreño resulta un poema casi cien versos más largo, llegando hasta cuatrocientos cuarenta y ocho, igualmente diferenciado en siete partes, respetando las divisiones del original. Sin embargo, los versos utilizados por Méndez son blancos endecasílabos, como ya hizo en su traducción de "?". Otra novedad introducida por el traductor y que no aparece en el texto de Hugo es la ruptura física del verso cuando encuentra un punto en mitad del mismo.

En la búsqueda de información sobre el literato salvadoreño Francisco Gavidia, quien es considerado uno de los principales difusores de la literatura francesa en El Salvador, encontramos trabajos suyos en otras publicaciones. Tal es el caso de "Yo trabajo" y de "Canción de Victor Hugo". "Yo trabajo", publicado en Centro América Intelectual, Año I, 1, 1903, es la traducción en prosa del poema "Je travaille" del poemario publicado después del fallecimiento de Hugo Toute la lyre.

\footnotetext{
${ }^{7}$ La obra Les Contemplations fue publicada en 1856, en el periodo en el que Hugo y su familia estaban en el exilio.
} 
El texto original está formado por cincuenta y seis versos alejandrinos franceses con rima rica en pareados (Hugo s.f.: 222-223). La traducción de Francisco Gavidia transforma en prosa todo el poema salvo la omisión de la mitad de dos versos consecutivos, el decimosexto y el decimoséptimo.

Con el título "Canción de Victor Hugo" Gavidia traduce el poema "Mes vers fuiraient, doux et frêles", perteneciente a "L'âme en fleur", segundo libro de Les Contemplations. El poema en francés está formado por tres estrofas de cuatro versos octosílabos y heptasílabos con rima rica en AbAb (Hugo 1964: 537). La traducción, publicada en la Revista del Ateneo de El Salvador, no 132 - 143, 1930, consta igualmente de doce versos distribuidos en tres estrofas de cuatro versos. Sin embargo, el tamaño de los versos es menos regular, ya que hay ocho octosílabos, dos pentasílabos, un tetrasílabo y un endecasílabo, todos con una rima consonante en $\mathrm{ABAB}$.

\section{Citas}

La Guirnalda Salvadoreña recoge poemas de Isaac Ruiz de Araujo precedidos por citas del autor francés. En "Misterios" y "Te Amo" aparecen dos citas de Victor Hugo en francés. La cita que precede "Misterios" es el vigésimo quinteto heptasílabo de los veinticinco que componen "Soirée en mer", poema incluido en Les Voix intérieures (Hugo 1950: 972). Reproducimos a continuación el texto que aparece en La Guirnalda Salvadoreña:

Chacun qu'il doute ou qu'il nie

Lutte en frayant son chemin;

Et l'eternelle harmonie

Pése [sic] comme une ironie

Sur tout ce tumulte humain.

En "Te Amo" podemos leer igualmente en francés una estrofa de cuatro versos de "Autre Chanson", de Les Chants du Crépuscule (Hugo 1950: 876). Esta poesía está formada por seis estrofas de cuatro versos que van alternando la medida de los versos por estrofas, a las tres estrofas impares le sigue un estribillo también de cuatro versos. La rima rica es respetada en todo el poema, repitiendo el esquema abab:

Je t'adore ange, je t'aime femme,

Dieu qui pour toi m'a completé,

A fait mon amour pour ton áme [sic]

Et ma regard pour ta beauté.

No obstante, aunque la intención de Ruiz Araujo es reproducir textualmente las estrofas de Hugo, en el caso de "Te Amo" podemos advertir un error al transcribir el poema francés: utiliza el posesivo femenino $m a$ en lugar de mon ante regard, cometiendo un error gramatical.

En el fragmento de "A mis hijos" de Ramón Uriarte de La Quincena del 15 de marzo de 1904 aparecen citas de Chateaubriand y de Victor Hugo. Este texto 
presenta dos citas del autor de Besançon, una en francés y sin identificar su origen y otra traducida al español y con la indicación de la obra de la que ha sido extraída. Sin embargo, las dos citas están relacionadas puesto que la primera, en francés, está formada por seis versos, uno de los cuales es la siguiente cita traducida al español. El problema es que Ramón Uriarte afirma que el verso que él reproduce en español procede de La Leyenda de los Siglos, cuando en realidad se trata de la duodécima de las veinte estrofas de seis versos que forman el poema "Dolor" incluido en Les Contemplations (Hugo 1964: 771):

Nier l'Être! à quoi bon? L'ironie âpre et noire

Peut-elle se pencher sur le gouffre et le boire,

Comme elle boit son propre fiel?

Quand notre orgueil le tait, notre douleur le nomme.

Le sarcasme peut-il, en crevant l'oeil à l'homme,

Crever les étoiles au ciel?

Y la frase traducida y erróneamente atribuida a La Légende des Siècles: Si nuestro orgullo le calla, le nombra nuestro dolor, que es la traducción del cuarto verso de la estrofa.

La sección "Notas y Noticias" de La Quincena del 1 de mayo de 1904 aparece una cita traducida del primer libro de Quatre-vingt-treize. No aparece el traductor ni tampoco la obra de la que ha sido extraída. La frase original y su traducción se reproducen a continuación:

Modeler une statue et lui donner la vie, c'est beau; modeler une intelligence et lui donner la vérité, c'est plus beau encore. (Hugo 1979: 159)

Modelar una estatua y darle la vida es grande, pero modelar una inteligencia y darle la verdad, es más grande todavía.

El 15 de marzo de 1905 y en esa misma revista, en la sección titulada "Para la Historia Literaria", se reproduce un artículo firmado por Joaquín Méndez publicado anteriormente en El Día de Guatemala, en el que se desvela el nombre de la poetisa salvadoreña que utilizaba el pseudónimo de "Esmeralda", Ana Dolores Arias. En el texto aparece una cita de Hugo que según Joaquín Méndez había seguido la poetisa salvadoreña: Si eres piedra, sé diamante; si eres planta, sé sensitiva; si eres hombre, sé amor. Esta cita es la traducción de la frase de Les Misérables perteneciente al cuarto capítulo del quinto libro del cuarto tomo (Hugo 1986: 953): Si vous êtes pierre, soyez aimant; si vous êtes plante, soyez sensitive; si vous êtes homme, soyez amour.

Veamos a continuación las citas que aparecen en El Repertorio. Completando la página en la que termina "El puñal malayo" de Tristan Bernard en el número de 15 de junio de 1906 de El Repertorio, nos encontramos la siguiente cita de Hugo: El pensamiento es un poder; y el talento una libertad. No hemos encontrado la obra de la que procede.

El 1 de octubre de 1906 podemos leer en la sección "Pensamientos" de $E l$ Repertorio otra frase de Hugo: Los que sirven a los traidores, son traidores 
también, traducción de Ceux qui servent les traîtres sont des traîtres! extraído de Histoire d'un crime (http://archives.ac-strasbourg.fr/pedago/lettres/victor\%20Hugo) ${ }^{8}$.

Otra cita de Hugo a final de página aparece en el número de El Repertorio del 15 de agosto de 1908: ¡El trueno! Parece que se oye la caída de un mueble en la cámara de los gigantes. Esta frase es una traducción de un fragmento del tercer libro de la segunda parte de Les travailleurs de la mer: Il y a du songe dans le tonnerre. Cette réalité brutale dans la région visionnaire a quelque chose de terrifiant. On croit entendre la chute d'un meuble dans la chambre des géants (Hugo 1866: 527).

\section{Referencias}

El 1 de abril de 1906 se publicó en El Repertorio la traducción del poema de Victor Hugo "Oh! N'insultez jamais une femme qui tombe" bajo el título en latín "Redemptio" y realizada por Gregorio Gutiérrez González que ya analizamos en el epígrafe dedicado a los textos literarios y sus traducciones. Este poema está situado después de un texto en prosa firmado por M. Arango titulado "La mujer caída" que nombra en dos ocasiones al autor francés e incluye otra traducción del primer cuarteto del poema. Así pues, el texto comienza haciendo referencia a la muerte del genio de Besançon y cómo las mujeres le mostraron su respeto tal y como él las respetó a ellas con la creación de ese poema.

El número del 1 de diciembre de 1906 de esa misma revista literaria comienza con un texto titulado "Poetas de la nueva generación" en el que se hace referencia a Victor Hugo, a Les Orientales y a su opinión de que no hay en poesía buenos ni malos asuntos, sino buenos y malos poetas.

El poeta salvadoreño Calixto Velado publica el 15 de junio de 1907 en $E l$ Repertorio dos poemas dedicados a sendos autores franceses, Hugo y Voltaire. "A Victor Hugo" es un poema formado por tres estrofas de cuatro versos endecasílabos con rima consonante en ABBA y ABAB.

En el tercer volumen de La Guirnalda Salvadoreña el autor salvadoreño Joaquín Aragón es autor de una estrofa de cuatro versos titulada "A Victor Hugo" en el que muestra o designa al autor francés como defensor de la poesía del siglo XIX.

En la edición del 1 de noviembre del año 1903 de La Quincena podemos leer bajo el epígrafe "Arte y Letras" un corto texto titulado "La casa de Victor Hugo" en la que se hace una descripción de la residencia parisina del poeta, convertida en museo. Además de la descripción de la casa donde se pueden ver también los dibujos y esculturas de Hugo, se enumeran las obras que el autor escribió allí.

En el texto en prosa de Rubén Darío "Por el Rhin", publicado en La Quincena en el número del 1 de enero de 1905, el poeta nicaragüense hace referencia al paso del maestro francés por este río.

\footnotetext{
${ }^{8}$ El sitio de la Académie de Strasbourg ha publicado en línea algunas obras de Victor Hugo, sin embargo no lo ha hecho con formato paginado, por lo que no podemos referenciar la página de la cita.
} 
La Quincena publica el 15 de noviembre de 1906 el texto en prosa "El retrato" de Jules Renard sin identificar el traductor ni la obra de la que ha sido extraído el texto. En él, este escritor narra cómo se sorprende al encontrar en el hogar de una humilde familia el retrato de Victor Hugo, desconocido para ellos, pero que les reconforta como si fuera el Dios invisible. El breve texto termina con la confesión del padre del motivo por el que lo puso en ese lugar: tapar un agujero de la chimenea.

El diario La Unión publicó el artículo titulado "Victor Hugo en América", firmado por D. D. Martinto. En él se hace una crítica del libro recién publicado 9 en el que el chileno José Antonio Soffia y el colombiano José Rivas Groot recopilan algunas de las poesías de Victor Hugo traducidas al español (Rodríguez-Arenas 2006: 243). Martinto realiza una dura crítica del libro comenzando por censurar la inclusión de traductores "peninsulares" en una obra en la que no tienen cabida. Continúa lamentando la falta de fidelidad de algunas versiones así como del nivel mediocre e incluso pésimo de ciertas traducciones. Sin embargo, felicita al autor por el orden cronológico en el que presenta los poemas, así como la traducción realizada por Andrés Bello de los poemas "Moisés" y "La oración por todos", que según dice, afirma Miguel Antonio Caro que llegan a ser superiores a las composiciones originales.

\section{Tablas y conclusiones}

En las tablas que presentamos a continuación podemos encontrar detallados los títulos publicados, la obra extraída, si aparece o hemos conseguido identificarla y el traductor cuando se especifica:

\begin{tabular}{|c|c|c|}
\hline Texto & Origen & Traductor \\
\hline "?" & "?" - Les Contemplations & Joaquín Méndez \\
\hline "A Enrique V" & $\begin{array}{l}\text { "À Henri V" - L'Année } \\
\text { terrible }\end{array}$ & - \\
\hline "A la bella imperiosa" & $\begin{array}{l}\text { "À la belle impérieuse" - Les } \\
\text { chansons des rues et des } \\
\text { bois }\end{array}$ & - \\
\hline $\begin{array}{l}\text { "A la niña enferma durante el } \\
\text { sitio" }\end{array}$ & $\begin{array}{l}\text { "À l'enfant malade pendant } \\
\text { le siège" - L'Année terrible }\end{array}$ & - \\
\hline
\end{tabular}

\footnotetext{
${ }^{9}$ Esta antología de poemas traducidos vio la luz en 1889 en Bogotá, bajo el título: Victor Hugo en América. Traducciones de ingenios americanos coleccionadas por José Antonio Soffia y José Rivas Groot (Rodríguez-Arenas 2006). Así pues el artículo data del mismo año en que se publicó el libro, tan solo cinco años después de la muerte de Victor Hugo.
} 


\begin{tabular}{|c|c|c|}
\hline $\begin{array}{l}\text { "A la que ha quedado en } \\
\text { Francia" }\end{array}$ & $\begin{array}{l}\text { "À celle qui est restée en } \\
\text { France" - Les } \\
\text { Contemplations } \\
\end{array}$ & Joaquín Méndez \\
\hline $\begin{array}{l}\text { "A un obispo que me llama } \\
\text { ateo y me excomulga" }\end{array}$ & $\begin{array}{l}\text { "À l'évêque qui m'appelle } \\
\text { athée" - L'Année Terrible }\end{array}$ & - \\
\hline "Canción de Victor Hugo" & $\begin{array}{l}\text { "Mes vers fuiraient, doux et } \\
\text { frêles" - Les Contemplations }\end{array}$ & Francisco Gavidia \\
\hline "Crepúsculo" & $\begin{array}{l}\text { "Crépuscule" - Les } \\
\text { Contemplations } \\
\end{array}$ & Teodoro Llorente \\
\hline "Ecos de una gran voz" & Actes et Paroles & - \\
\hline "El Alfabeto" & Alpes et Pyrénées & - \\
\hline "El derecho de la miseria" & $x_{1}$ & $\begin{array}{l}\text { Marcos Rafael Blanco- } \\
\text { Belmonte }\end{array}$ \\
\hline "El Momotombo" & $\begin{array}{l}\text { "L'inquisition - Les raisons } \\
\text { du Momotombo" - La } \\
\text { Légende des siècles }\end{array}$ & - \\
\hline "La libertad de la prensa" & Actes et Paroles & A. Gordon de Simón \\
\hline "La naturaleza" & $\begin{array}{l}\text { "La Nature" - Les } \\
\text { Contemplations } \\
\end{array}$ & Joaquín Méndez \\
\hline "La novia del timbalero" & $\begin{array}{l}\text { "La fiancée du timbalier" - } \\
\text { Odes et Ballades } \\
\end{array}$ & José Juan Tablada \\
\hline "Las Estrellas" & "Extase"-Les Orientales & - \\
\hline "Líneas" & $\begin{array}{l}\text { "Je n'ai pas de palais } \\
\text { épiscopal en ville" - L'Année } \\
\text { Terrible }\end{array}$ & - \\
\hline "Los Genios", "Homero" & William Shakespeare & - \\
\hline "Los insultadores" & $\begin{array}{l}\text { "Les insulteurs" - L'Année } \\
\text { Terrible }\end{array}$ & - \\
\hline "Redemptio" & $\begin{array}{l}\text { "Oh! N'insultez jamais une } \\
\text { femme qui tombe" - Les } \\
\text { Chants du crépuscule }\end{array}$ & $\begin{array}{l}\text { Gregorio Gutiérrez } \\
\text { González }\end{array}$ \\
\hline "Religión" & \begin{tabular}{|l} 
"Religio" - Les \\
Contemplations \\
\end{tabular} & Joaquín Méndez \\
\hline "Remember fúnebre" & - & Juan Antonio Solórzano \\
\hline "San Pablo" & William Shakespeare & - \\
\hline "Stella" & "Stella" - Les Châtiments & Francisco Gavidia \\
\hline "Toute la Lira" & $\begin{array}{l}\text { "Vous m'avez éprouvé" - } \\
\text { Toute la lyre }\end{array}$ & Leopoldo Díaz \\
\hline
\end{tabular}




\begin{tabular}{|l|l|c|}
\hline "Una carta" & Actes et Paroles & - \\
\hline $\begin{array}{l}\text { "Victor Hugo pintado por sí } \\
\text { mismo" }\end{array}$ & - & \\
\hline "Yo trabajo" & "Je travaille" - Toute la lyre & Francisco Gavidia \\
\hline \multicolumn{1}{|c|}{-} & William Shakespeare & - \\
\hline
\end{tabular}

\begin{tabular}{|l|l|c|}
\hline Texto & Origen & Autor o traductor \\
\hline Cita & $\begin{array}{l}\text { "Autre chanson" - Les chants } \\
d u \text { Crépuscule }\end{array}$ & Isaac Ruiz de Araujo \\
\hline Cita & $\begin{array}{l}\text { "Dolor" - Les } \\
\text { Contemplations }\end{array}$ & Ramón Uriarte \\
\hline Cita & $\begin{array}{l}\text { "Dolor" - Les } \\
\text { Contemplations }\end{array}$ & Ramón Uriarte \\
\hline Cita & $\begin{array}{l}\text { "Soirée en mer" - Les voix } \\
\text { intérieures }\end{array}$ & Isaac Ruiz de Araujo \\
\hline Cita & Histoire d'un crime & - \\
\hline Cita & Les Misérables & Joaquín Méndez \\
\hline Cita & Les travailleurs de la mer & - \\
\hline Cita & Quatre-vingt-treize & - \\
\hline Cita & \multicolumn{1}{|c|}{-} \\
\hline
\end{tabular}

\begin{tabular}{|l|l|l|}
\hline Referencia & Origen & Autor \\
\hline "A Victor Hugo" & - & Joaquín Aragón \\
\hline "A Victor Hugo" & - & Calixto Velado \\
\hline "El retrato" & - & Jules Renard \\
\hline "La Casa de Victor Hugo" & - & - \\
\hline "La Mujer caída" & - & M. Arango \\
\hline "Poetas de nueva generación" & - & - \\
\hline "Por el Rhin" & - & Rubén Darío \\
\hline "Victor Hugo en América" & - & D. D. Martinto \\
\hline
\end{tabular}

El análisis de estas tablas a modo de resumen nos permite ver que las obras de Victor Hugo presentes en los autores que escriben en las publicaciones consultadas abarcan la totalidad de su producción literaria, desde sus inicios (Odes et Ballades), pasando por su largo periodo en el exilio (Les Châtiments) o bien las escritas ya a su retorno en Francia (Quatre-vingt-treize). Sin embargo, hay cuatro obras que aparecen en más ocasiones que el resto: Les Contemplations, con siete textos o referencias, lo que supone el 15\%; L'année terrible con cinco, un 11\%; y Actes et paroles y William Shakespeare con tres, 6,5\% cada una. 
En la mitad de las traducciones no se especifica el nombre del traductor, limitándose a catorce el número de ocasiones en que esto ocurre sobre los veintinueve que son en total. En el caso de las referencias o alusiones, de las ocho que son, en seis de ellas encontramos la firma del autor que la utiliza, lo que nos indica que en un $75 \%$ estos escritores quieren que aparezca su nombre, mostrando así su conocimiento del poeta francés o su obra. En cuanto a las citas, cinco autores identificados utilizan alguna cita de Hugo en sus textos, lo que reduce el porcentaje a un 56\%, encontrándonos así con cuatro citas que no están incluidas en un texto firmado. Por último, en tres ocasiones se reproduce la cita en francés de las nueve que son en total, es decir, un $33 \%$.

También podemos advertir el cambio de formato en algunas ocasiones en las que el traductor modifica el poema original transformándolo en un texto en prosa. Hemos encontrado la traducción de veinte poesías de Victor Hugo, de las cuales cinco han sido modificadas convirtiéndolas en prosa, lo que hace que un elevado porcentaje, el $20 \%$ de los textos, hayan sido trasladados del género poético al narrativo. Los nueve textos restantes estaban en prosa y se han traducido en prosa.

Como conclusión final podemos afirmar que la presencia de Victor Hugo se deja patente en estas publicaciones salvadoreñas gracias a la utilización de diferentes recursos, la traducción, paráfrasis, cita o referencia, lo que nos puede dar una idea de la repercusión que la obra del poeta francés tuvo en este periodo en las letras salvadoreñas. Por otro lado, podemos advertir igualmente que al contrario que otros autores de los que sólo hemos encontrado traducciones procedentes de una obra o tan sólo en poesía o en prosa, en el caso de Victor Hugo se recurre a textos extraídos de publicaciones muy dispares formal, temporal y temáticamente.

\section{REFERENCIAS BIBLIOGRÁFICAS}

BELLINI, G. (1997): Nueva historia de la literatura hispanoamericana, Madrid, Editorial Castalia.

Centro América Intelectual, (1903), Año I, 1.

Diccionario de la Lengua Española (2001), 22 $2^{\mathrm{a}}$ Edición, Real Academia Española, Versión electrónica disponible en: www.rae.es.

El Repertorio, (1906, 1907, 1908), San Salvador, en Biblioteca Especializada del Museo Nacional de Antropología David J. Guzmán.

HUGO, V. (1866): Les travailleurs de la mer. Bibliothèque électronique du Québec. Volume 80, version 1.01. http://beq.ebooksgratuits.com/vents/Hugo-travailleurs.pdf. Fecha de consulta: 06/10/2010.

HUGO, V. (1877-1878): Histoire d'un crime. Sitio web de la Académie de Strasbourg: http://archives.ac-strasbourg.fr/pedago/lettres/victor\%20Hugo/. Fecha de consulta: $06 / 10 / 2010$.

HUGO, V. (1950): Euvres Poétiques, vol. I, Bibliothèque de la Pléiade, Gallimard, Paris.

HUGO, V. (1964): Euvres Poétiques, vol. II, Bibliothèque de la Pléiade, Gallimard, Paris.

HUGO, V. (1974): CEuvres Poétiques, vol. III, Bibliothèque de la Pléiade, Gallimard, Paris. 
HUGO, V. (1979): Quatre-vingt-treize, Éditions Gallimard, Folio Classique, Paris.

HUGO, V. (1987): Euvres Complètes - Voyages, Éditions Robert Laffont, Paris.

HUGO, V. (1992): Écrits sur la peine de mort, Actes Sud.

HUGO, V. (2000): Les Misérables, Bibliothèque de la Pléiade, Gallimard, Paris.

HUGO, V. (2003): William Shakespeare, Garnier Flammarion.

HUGO, V. (Sin fecha): Oeuvres romanesques, dramatiques et poétiques. Toute la lyre. Edito-Service. Genève.

JIMÉNEZ-CERVANTES ARNAO, M. (2008): “Un análisis de la traducción de "Stella" de Victor Hugo por Francisco Gavidia" in Cartaphilus, n ${ }^{\circ}$ 3, 101-111, ISSN: 1887-5238, http://revistas.um.es/cartaphilus/article/viewFile/23561/22821

La Quincena (1903, 1904, 1906, 1907), San Salvador, en Biblioteca Especializada del Museo Nacional de Antropología David J. Guzmán.

La Quincena, (1905), San Salvador, en Colecciones Especiales de la Biblioteca P. Florentino Idoate, S.J. de la Universidad Centroamericana José Simeón Cañas, U.C.A.

La Unión (1889), San Salvador, en Colecciones Especiales de la Biblioteca P. Florentino Idoate, S.J. de la Universidad Centroamericana José Simeón Cañas, U.C.A.

MAYORGA RIVAS, R. (1977): La Guirnalda Salvadoreña, Tomos I, II y III, Ministerio de Educación. Dirección de publicaciones, San Salvador, en Biblioteca Especializada del Museo Nacional de Antropología David J. Guzmán.

Revista del Ateneo de El Salvador, (1930), n 132 - 143.

RODRÍGUEZ-ARENAS, F. M. (2006): Bibliografía de la literatura colombiana del siglo XIX. Tomos I y II. Stockcero USA.

ROSA, A. (1985): Victor Hugo. L'Éclat d'un siècle, Éditions Messidor, Disponible en: http://groupugo.div.jussieu.fr/ 